\title{
Methanol fixation for scanning electron microscopy of plants
}

\author{
Ki Woo Kim ${ }^{1,2}$
}

\begin{abstract}
Plant specimens for scanning electron microscopy (SEM) are commonly treated using standard protocols. Conventional fixatives consist of toxic chemicals such as glutaraldehyde, paraformaldehyde, and osmium tetroxide. In 1996, methanol fixation was reported as a rapid alternative to the standard protocols. If specimens are immersed in methanol for $30 \mathrm{~s}$ or longer and critical-point dried, they appear to be comparable in preservation quality to those treated with the chemical fixatives. A modified version that consists of methanol fixation and ethanol dehydration was effective at preserving the tissue morphology and dimensions. These solvent-based fixation and dehydration protocols are regarded as rapid and simple alternatives to standard protocols for SEM of plants.
\end{abstract}

Keywords: Fixation, Glutaraldehyde, Methanol

\section{Introduction}

Plant specimens must be fixed for SEM because they cannot withstand water removal by the vacuum system without distortion (Pathan et al. 2010). A standard protocol for SEM of plant specimens comprises a series of procedures: chemical fixation, dehydration, critical point drying, and metal coating (Yuan et al. 2020). The chemical fixation involves immersing specimens in solvents such as glutaraldehyde, paraformaldehyde, and osmium tetroxide for various periods (Chieco et al. 2012). Depending on the specimen dimension, this protocol usually takes several hours (Neinhuis and Edelmann 1996). Meanwhile, dried materials such as seeds, wood blocks, and herbarium specimens are metal coated for SEM observations without any other preparations. Using either variable pressure or low-temperature SEM also reduces labor and time for specimen preparations (Kim 2013; Talbot and White 2013b).

A well-known artefact of preparing biological specimens for SEM is the tissue shrinkage (up to $75 \%$ of their original size) during fixation, dehydration, and critical point drying steps (Talbot and White 2013a). It is necessary to find a better fixative that allows morphological preservation with

\footnotetext{
Correspondence: kiwoo@knu.ac.kr

'School of Ecology and Environmental System, Kyungpook National University, Sangju 37224, Republic of Korea

${ }^{2}$ Tree Diagnostic Center, Kyungpook National University, Sangju 37224, South Korea
}

reduced labor and time. Another property of a good fixainsights and technical guidance about the methanol fixation as an alternative to standard protocols for SEM of plants.

\section{ol fixation}

anol $\left(\mathrm{CH}_{3} \mathrm{OH}\right)$ is the simplest alcohol and highly polar bot and White 2013a). As traditional coagulant fixatives of dehydrant types, methanol and ethanol maintain tissue ments, which might be due to the removal of water from the cell walls and thereby increased hydrogen bonding beIn 1996, Neinhuis and Edelmann in Germany first reported the practical use of methanol as a fixative of plant surfaces for SEM. They immersed plant specimens in methanol for $30 \mathrm{~s}$ or longer and dried them using a critical point drier (Table 1). For comparison, 
Table 1 Two methanol fixation protocols for scanning electron microscopy of plant specimens

\begin{tabular}{ll}
\hline Methanol fixation $^{\text {a }}$ & $\begin{array}{l}\text { Methanol fixation - ethanol } \\
\text { dehydration }\end{array}$ \\
\hline Immersion in 100\% methanol & Fixation in 100\% methanol \\
for $30 \mathrm{~s}$ & for 10 min \\
& $\begin{array}{l}\text { Dehydration in } 100 \% \text { ethanol } \\
\text { for } 30 \text { min }\end{array}$ \\
& (two times) \\
Critical point drying & Critical point drying \\
\hline
\end{tabular}

afrom Neinhuis and Edelmann 1996

bfrom Talbot and White 2013a

they employed the standard protocol for SEM. The methanol fixation/dehydration protocol revealed overall smooth epidermis of rye coleoptiles (Fig. 1a). Meanwhile, a regular folding due to shrinking was observed in the standard protocol treatment (Fig. 1b). Salvinia auriculata trichomes were assumed to be better preserved using the methanol fixation/dehydration protocol than those treated with the standard protocol (Fig. 1c and d). Taken together, the methanol incubation for fixation/dehydration was proposed as a suitable treatment prior to critical point drying of plant specimens (Neinhuis and Edelmann 1996). Owing to this instant fixation, specimen shrinkage would be prevented, resulting in an improved preservation of cell dimensions (Zelko et al. 2012). With regard to plant epicuticular waxes, the use of methanol as a fixative has been considered as desirable since methanol is relatively less damaging to plant waxes as compared to ethanol or acetone (Pathan et al. 2010).

\section{Ethanol fixation}

Another solvent-based fixation was proposed to reduce the health hazards of formalin-based fixatives. Ethanol is also a widely used fixative that removes water and coagulates proteins in tissues (Eltoum et al. 2001). Commercialized as FineFIX ${ }^{\mathrm{nt}}$, an ethanol-based fixative for SEM does not contain formalin (Chieco et al. 2012). Plant leaves and trichomes treated with the ethanol-based fixative were comparable to those treated with the standard fixative in morphological preservation.

\section{Examples of methanol fixation since 1996 Leaf stomata}

Leaf and stem specimens of rice were fixed and dehydrated with methanol, and critical-point dried (Das and Baruah 2008). Stomatal frequencies (number of stomata $\mathrm{mm}^{-2}$ ) were measured from the methanol-fixed leaf specimens (Fig. 2a). The morphological preservation was sufficient for the xylem observation in stems.

\section{Leaf sclerenchyma}

Cross sections from peltate-leaf plant Colocasia fallax were dissected using a razor blade (Sacher et al. 2019). They were fixed in methanol and critical-point dried. Sclerenchyma
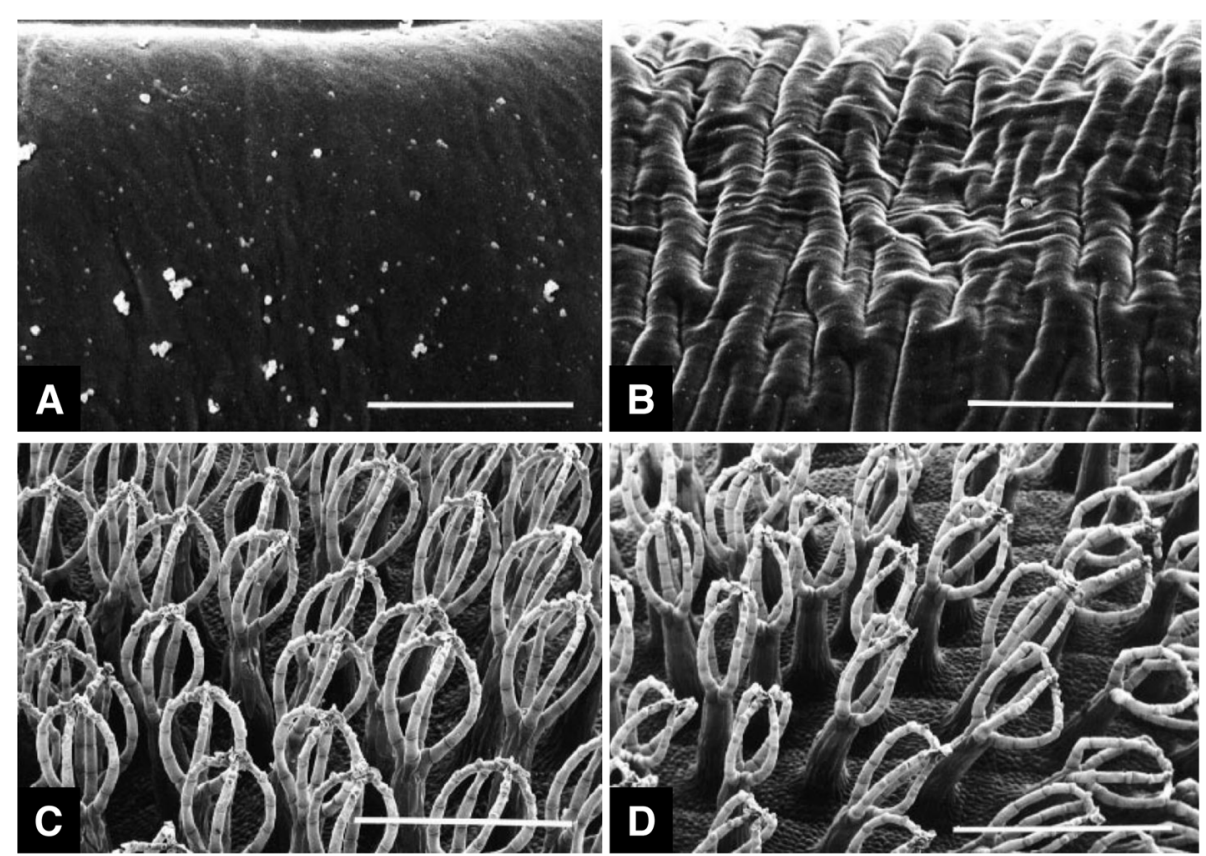

Fig. 1 Scanning electron micrographs of leaves. (Left) Specimens fixed and dehydrated in methanol followed by critical point drying. (Right) Specimens treated with a conventional protocol. $\mathbf{a}$ and $\mathbf{b}$ Rye coleoptiles. Bars $=5 \mu \mathrm{m}$. $\mathbf{c}$ and $\mathbf{d}$ Salvinia auriculata trichomes. Bars $=1 \mathrm{~mm}$. From Neinhuis and Edelmann 1996 with permission from the publisher 

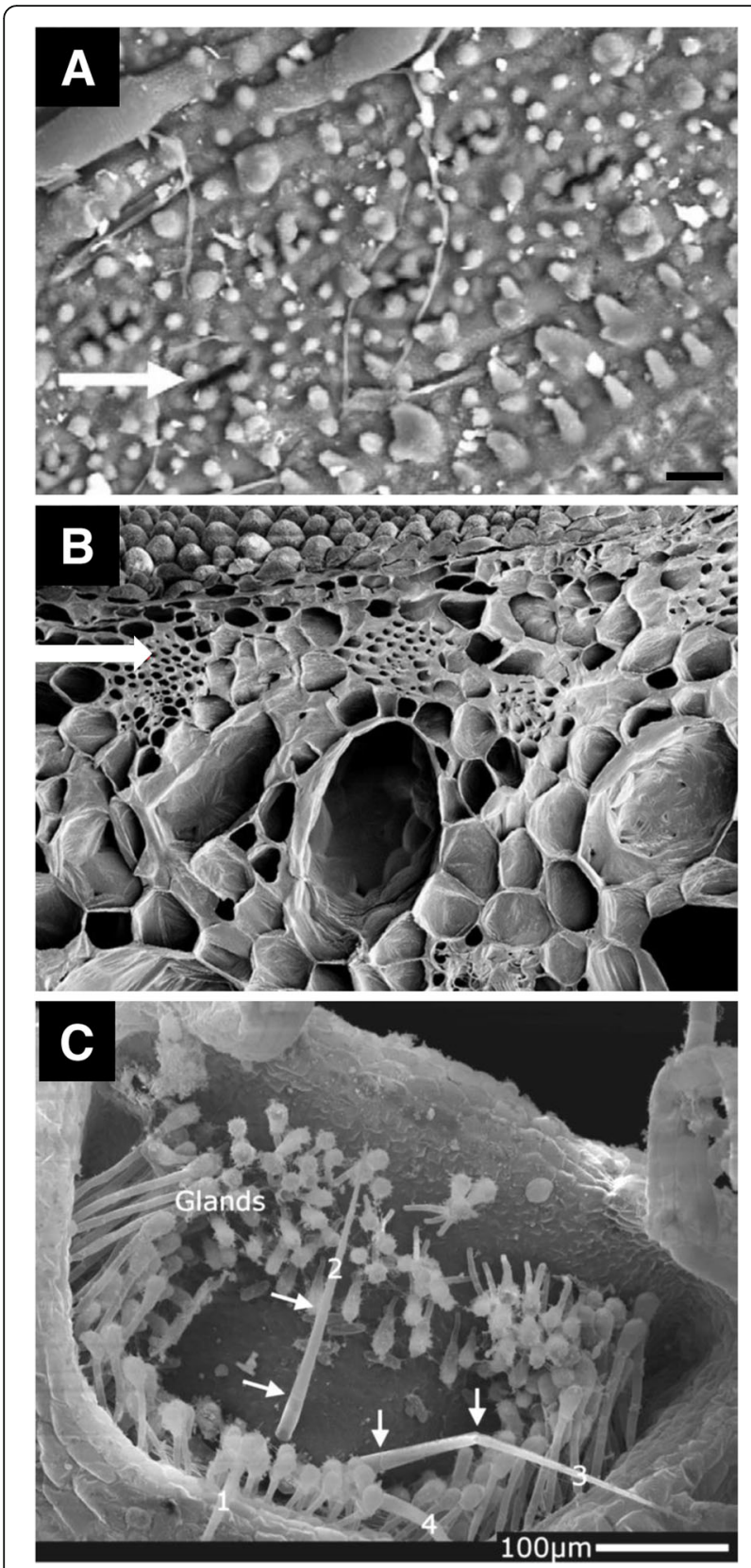

Fig. 2 Scanning electron micrographs of methanol-fixed plants. a Rice leaf. Arrow $=$ stoma. Bar $=10 \mu \mathrm{m}$. $\mathbf{b}$ Cross section of Colocasia fallax leaf fixed in methanol. Arrow = sclerenchyma. $\mathbf{c}$ Suction trapdoor of a carnivorous plant Utricularia australis. Note four trigger hairs (1-4). Arrows = cell-to-cell junctions. A: from Das and Baruah 2008; B: from Sacher et al. 2019; C: from Poppinga et al. 2017 with permission from the publisher

could be distinguished from other tissues in the methanolfixed cross sectioned leaf specimens (Fig. 2b).

\section{Carnivorous trap}

An aquatic carnivorous plant Utricularia australis has suction traps for animal capturing. The trap was fixed in methanol and critical-point dried (Poppinga et al. 2017). Glands and trigger hairs were found in the trapdoor (Fig. 2c). Cell-to-cell junctions could be discernable on the trigger hairs.

\section{Fruit skin}

The integrity of tomato fruit was investigated using SEM (Bargel and Neinhuis 2005). Cross sections of fruit were fixed in methanol for $1 \mathrm{~min}$ and critical-point dried. The cuticles and epidermal cell walls could be identified at different ripening stages.

\section{Variations of methanol fixation}

In 2013, Talbot and White in Australia proposed another version of the methanol fixation (Table 1). They modified the original methanol fixation protocol to preserve the dimensions of critical point-dried specimens. Leaves of Arabidopsis thaliana were (i) fixed in $3 \%$ glutaraldehyde overnight at $4{ }^{\circ} \mathrm{C}$, (ii) fixed in methanol for $10 \mathrm{~min}$ followed by methanol dehydration and critical point drying with methanol, and (iii) fixed in methanol for $10 \mathrm{~min}$ followed by ethanol dehydration and critical point drying with ethanol. Overall, the epidermis treated with the standard fixative (Fig. 3a) was not well fixed as those with the solvent-based protocols (Fig. $3 \mathrm{~b}$ and c) in preservation quality. The methanol fixation followed by ethanol dehydration and critical point drying with ethanol resulted in the least cell wall wrinkling with negligible cell collapse or cell wall folding (Talbot and White 2013a).

As another example, forage grass roots were fixed in methanol at room temperature overnight and dehydrated with $100 \%$ ethanol three times (Saleh et al. 2019). SEM revealed roots and their endophytic bacteria in the rhizosphere. Root hairs, rod-shaped bacteria, and bacterial aggregates could be resolved.

The variation of methanol fixation was also tested with bean leaves. The leaves were (i) fixed in methanol for 20-40 s followed by air-drying, and (ii) fixed in liquid nitrogen-cooled methanol for $20-40 \mathrm{~s}$ and liquid nitrogen followed by freeze-drying (Pathan et al. 2010). Both protocols exhibited partial preservation of leaf epidermis (Fig. 4). The latter protocol was evaluated as better than the former one in preservation quality. These findings indicate the importance of a drying procedure even after methanol fixation.

\section{Methanol fixation for fluorescence microscopy}

Plant specimens are fixed and stored in methanol for the high-throughput quantification of cell and tissue structures (Atkinson and Wells 2017). Root anatomical features including phloem, xylem, epidermis, and endodermis were observed in the methanol-fixed 

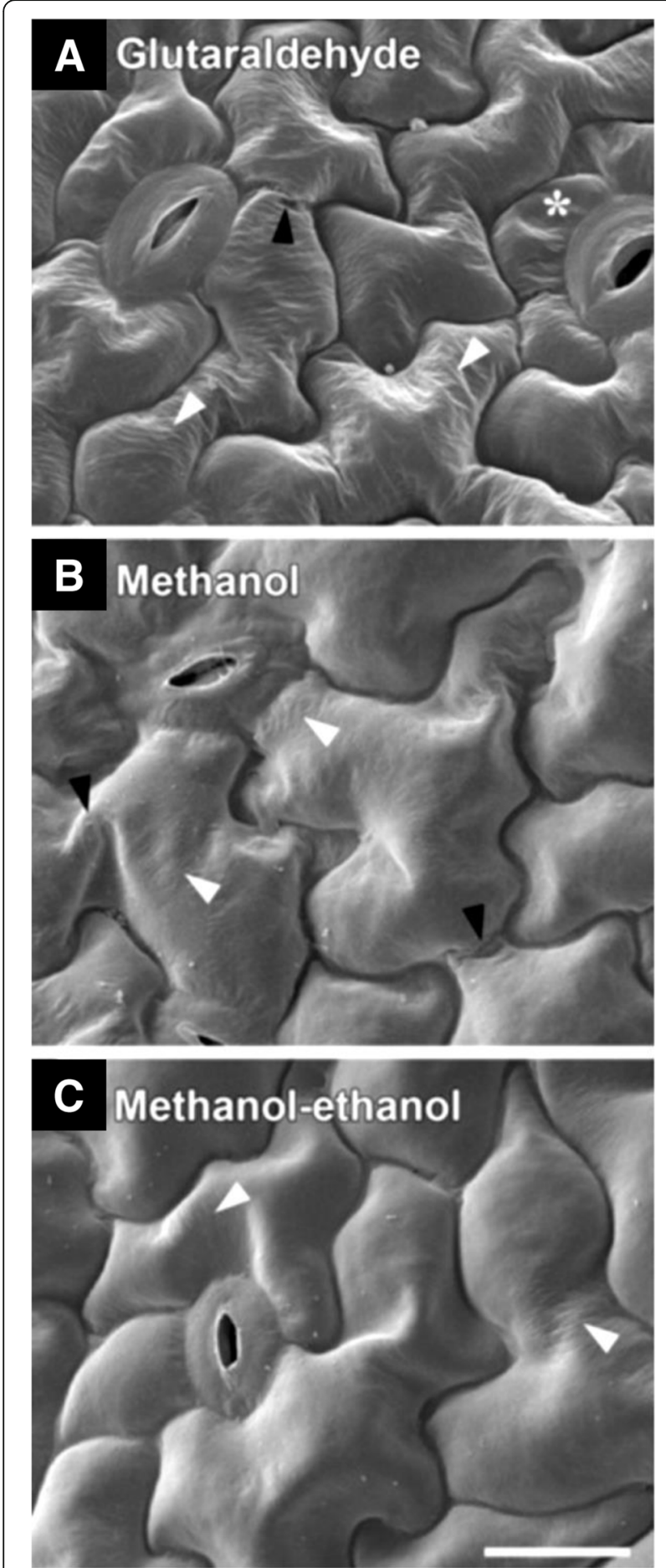

Fig. 3 Scanning electron micrographs of Arabidopsis thaliana leaves. a Specimen fixed in glutaraldehyde. b Specimen fixed in methanol followed by critical point drying in methanol. c Specimen fixed in methanol followed by ethanol dehydration and critical point drying in ethanol. Star = partial cell collapse. Black arrowhead = cell wall folding. White arrowhead $=$ cell wall wrinkle. $\mathrm{Bar}=20 \mu \mathrm{m}$. From Talbot and White 2013a with permission from the publisher
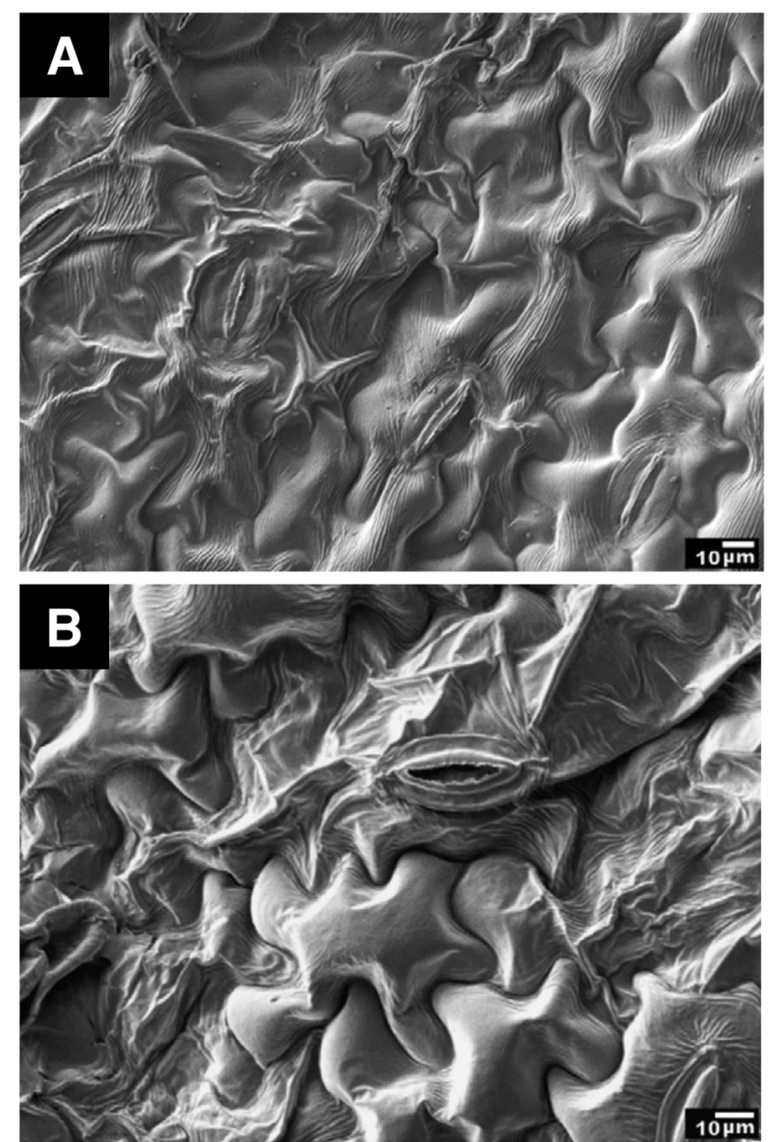

Fig. 4 Scanning electron micrographs of bean leaves. a Specimen fixed in methanol for 20-40 s followed by air-drying. b Specimen fixed in liquid nitrogen-cooled methanol for 20-40 s and liquid nitrogen followed by freeze-drying. Bars $=10 \mu \mathrm{m}$. From Pathan et al. 2010 with permission from the publisher

wheat (Fig. 5). Methanol fixation preserved root elasticity and did not influence fluorescent staining of root specimens, which was different from the other fixatives (Zelko et al. 2012).

\section{Cautions}

The use of methanol as a single fixative is not always effective at preserving cell morphology. In rat liver cells, methanol was evaluated for its performance as a fixative of cytoskeletal components for immunofluorescence. However, such a methanol-based precipitation fixation was not suitable, as it caused numerous artefacts due to cell shrinkage (Vielkind and Swierenga 1989).

Human breast cancer cells were fixed in methanol at $-20^{\circ} \mathrm{C}$ for $10 \mathrm{~min}$ and dehydrated in ethanol and critical-point dried. The methanol fixation resulted in poor preservation of plasma membrane integrity (Hoetelmans et al. 2001). The authors objected to the use of methanol as a single fixative in the case of 


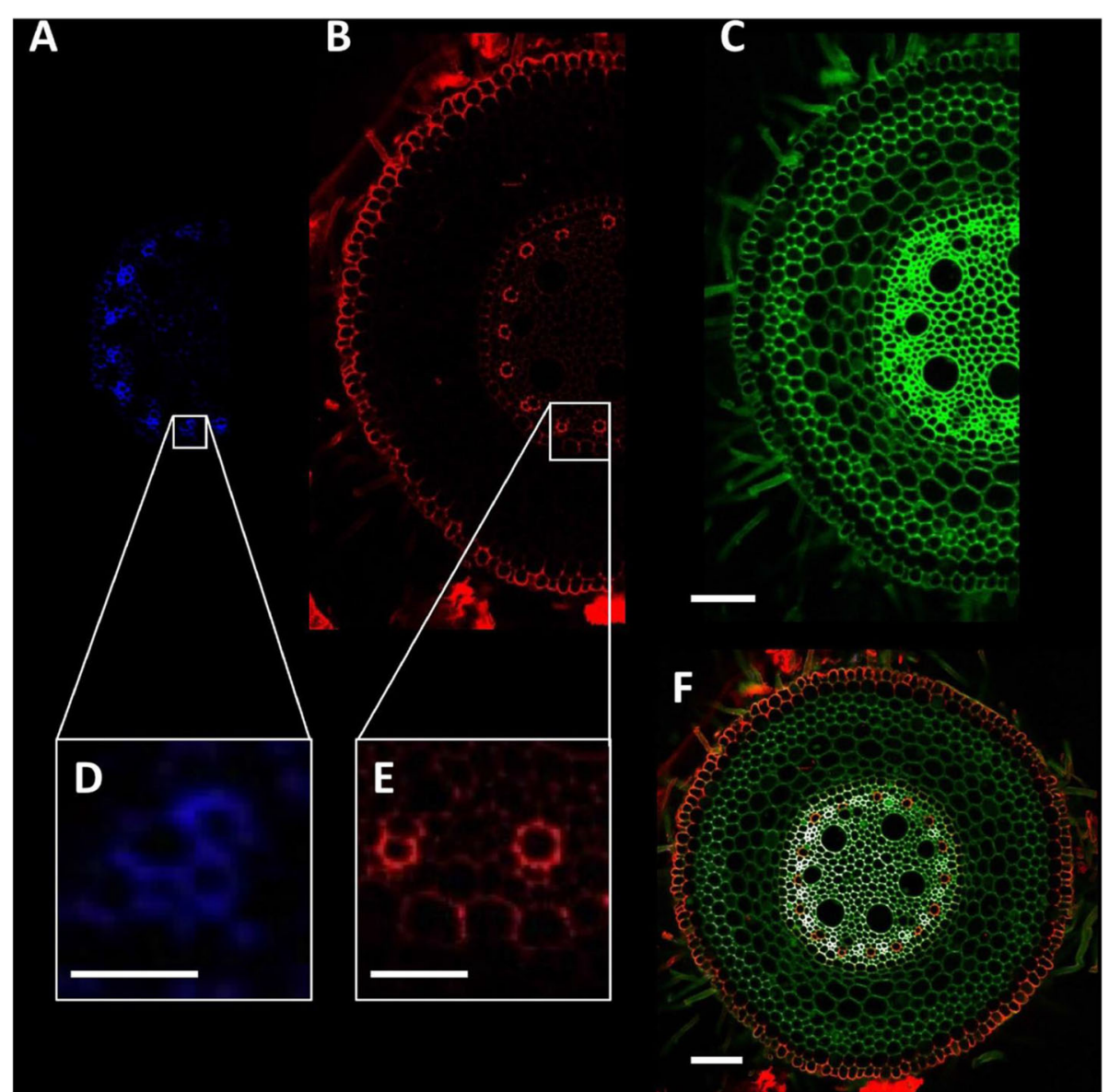

Fig. 5 Confocal laser scanning micrographs of wheat root cells. a and $\mathbf{d}$ Phloem. b Autofluorescence signal. c Total cell wall image. e Xylem. $\mathbf{f}$ Composite image of (a), (b), and (c). Bars $=100 \mu \mathrm{m}(\mathbf{a}-\mathbf{c}, \mathbf{f}), 25 \mu \mathrm{m}(\mathbf{d})$, and $50 \mu \mathrm{m}(\mathbf{e})$. From Atkinson and Wells 2017 with permission from the publisher

human breast cancer cells. In general, aldehyde fixation protocols perform significantly better than organic solvents with less severe loss of biochemical information in animals (Hobro and Smith 2017). These findings suggest that methanol fixation may be effective only in plants.

\section{Conclusions}

Methanol fixation was developed as an alternative to conventional protocols for SEM observations of plants. Immersion in methanol for $10 \mathrm{~min}$ and critical point drying were appropriate to preserve the tissue morphology of various plants. Simultaneous fixation and dehydration in methanol has been recognized as a rapid alternative to standard aldehydebased fixatives and solvent-based dehydration steps. A modified version was developed to include methanol fixation and ethanol dehydration, which took longer for SEM observations than the original protocol. However, it was regarded to provide a better tissue preservation than the original protocol. This solvent-based fixation and dehydration does not necessitate the use of toxic chemicals such as glutaraldehyde, paraformaldehyde, and osmium tetroxide. These findings suggest that the methanol fixation and ethanol dehydration may be used widely to a variety of plant specimens.

Abbreviation

SEM: Scanning electron microscopy

Acknowledgements

Not applicable.

\section{Author's contributions}

The author designed and wrote the manuscript. The author(s) read and approved the final manuscript.

\section{Authors' information}

Not applicable.

\section{Funding}

Not applicable.

Availability of data and materials Data and materials available on request. 


\section{Competing interests}

The author declares no competing interests relevant to this article.

Received: 18 March 2020 Accepted: 6 April 2020

Published online: 25 May 2020

\section{References}

J.A. Atkinson, D.M. Wells, An updated protocol for high throughput plant tissue sectioning. Front. Plant Sci. 8, 1721 (2017)

H. Bargel, C. Neinhuis, Tomato (Lycopersicon esculentum mill.) fruit growth and ripening as related to the biomechanical properties of fruit skin and isolated cuticle. J. Expt. Bot. 56, 1049-1060 (2005)

C. Chieco, A. Rotondi, L. Morrone, F. Rapparini, R. Baraldi, An ethanol-based fixation method for anatomical and micro-morphological characterization of leaves of various tree species. Biotech. Histochem. 88, 109-119 (2012)

K. Das, K.K. Baruah, Methane emission associated with anatomical and morphophysiological characteristics of rice (Oryza sativa) plant. Physiol. Planta. 134, 303-312 (2008)

H.G. Edelmann, Characterization of hydration-dependent wall-extensible properties of rye coleoptiles: Evidence for auxin-induced changes of hydrogen bonding. J. Plant Physiol. 145, 491-497 (1995)

I. Eltoum, J. Fredenburgh, R.B. Myers, W.E. Grizzle, Introduction to the theory and practice of fixation of tissues. J. Histotechnol. 24, 173 (2001)

A.J. Hobro, N.I. Smith, An evaluation of fixation methods: Spatial and compositional cellular changes observed by Raman imaging. Vib. Spectrosc. 91, 31-45 (2017)

R.W.M. Hoetelmans, F.A. Prins, I. Cornelese-ten Velde, J. van der Meer, C.J.H. van de Velde, J.H. van Dierendonck, Effects of acetone, methanol, or paraformaldehyde on cellular structure, visualized by reflection contrast microscopy and transmission and scanning electron microscopy. Appl. Immnuohistochem. Mol. Morphol. 9, 346-351 (2001)

K.W. Kim, Ambient variable pressure field emission scanning electron microscopy for trichome profiling of Plectranthus tomentosa by secondary electron imaging. Appl. Microsc. 43, 34-39 (2013)

C. Neinhuis, H.G. Edelmann, Methanol as a rapid fixative for the investigation of plant surfaces by SEM. J. Microsc. 184, 14-16 (1996)

A.K. Pathan, J. Bond, R.E. Gaskin, Sample preparation for scanning electron microscopy of plant surfaces-horses for courses. Micron 39, 1049-1061 (2010)

S. Poppinga, L.E. Daber, A.S. Westermeier, S. Kruppert, M. Horstmann, R. Tollrian, T. Speck, Biomechanical analysis of prey capture in the carnivorous southern bladderwort (Utricularia australis). Sci. Rep. 7, 1776 (2017)

M. Sacher, T. Lautenschläger, A. Kempe, C. Neinhuis, Umbrella leavesbiomechanics of transition zone from lamina to petiole of peltate leaves. Bioinspir. Biomim. 14, 046011 (2019)

D. Saleh, J. Jarry, M. Rani, K.A. Aliferis, P. Seguin, S.H. Jabaji, Diversity, distribution and multi-functional attributes of bacterial communities associated with the rhizosphere and endosphere of timothy (Phleum pratense L.). J. Appl. Micobiol. 127, 794-811 (2019)

M.J. Talbot, R.G. White, Methanol fixation of plant tissue for scanning electron microscopy improves preservation of tissue morphology and dimensions. Plant Meth. 9, 36 (2013a)

M.J. Talbot, R.G. White, Cell surface and cell outline imaging in plant tissues using the backscattered electron detector in a variable pressure scanning electron microscope. Plant Meth. 9, 40 (2013b)

U. Vielkind, S.H. Swierenga, A simple fixation procedure for immunofluorescent detection of different cytoskeletal components within the same cell. Histochemistry 91, 81-88 (1989)

J. Yuan, X. Wang, H. Zhou, Y. Li, J. Zhang, S. Yu, M. Wang, M. Hao, Q. Zhao, L. Liu, M. Li, J. Li, Comparison of sample preparation techniques for inspection of leaf epidermises using light microscopy and scanning electronic microscopy. Front. Plant Sci. 11, $133(2020)$

I. Zelko, A. Lux, T. Sterckeman, M. Martinka, K. Kollárová, D. Lišková, An easy method for cutting and fluorescent staining of thin roots. Ann. Bot. 110, 475-478 (2012)

\section{Publisher's Note}

Springer Nature remains neutral with regard to jurisdictional claims in published maps and institutional affiliations.

\section{Submit your manuscript to a SpringerOpen ${ }^{\circ}$ journal and benefit from:}

- Convenient online submission

- Rigorous peer review

- Open access: articles freely available online

- High visibility within the field

- Retaining the copyright to your article

Submit your next manuscript at $\boldsymbol{\nabla}$ springeropen.com 